\title{
Imaging Assessment of Paediatric Crohn's Disease: a Literature Review
}

\author{
S Salerno, MC Terranova, F Vernuccio, D Picone, C Tudisca, G Lo Re, R Lagalla \\ Department of Radiology, University Hospital Policlinico Paolo Giaccone, Palermo, Italy
}

\begin{abstract}
Owing to the frequent absence of specific symptoms, diagnosis of Crohn's disease may be delayed, potentially leading to important patient morbidity, growth failure, pubertal delay, or a complicated form of the disease. In paediatric patients with Crohn's disease, radiation protection requires special consideration, and choosing the most appropriate imaging modality is crucial. All radiologists should be familiar with the main imaging characteristics of Crohn's disease. Therefore, the present study reviews the current literature on imaging modalities and main imaging characteristics of Crohn's disease. Magnetic resonance imaging is recommended for diagnosis of Crohn's disease in paediatric patients because it is able to precisely define the presence, the extent, the grade of activity, and the principal complications of the disease without any radiation exposure.
\end{abstract}

Key Words: Child; Crohn disease; Magnetic resonance imaging; Tomography, X-ray computed; Ultrasonography

\section{中文摘要}

\section{小兒克隆氏症的影像學評估：文獻綜述}

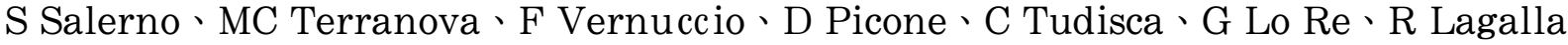

克隆氏症大多沒有明顯特定症狀, 故可能出現診斷延誤, 可導致嚴重的併發症、發育障礙、青春期 發育延緩或複雜的疾病。為小兒克羅恩氏症患者進行輻射保護時須加緊注意, 選擇最合適的成像方 式至關重要。所有放射科醫師須熟悉克隆氏症的主要影像學特徵。因此, 本研究回顧目前有關克隆 氏症成像方式和主要影像學特徵的文獻, 並建議以磁共振成像診斷小兒克隆氏症, 因它能精確定義 疾病的存在、程度、活躍程度和主要併發症, 並避免輻射。

\footnotetext{
Correspondence: Dr G Lo Re, Department of Radiology, University Hospital Policlinico Paolo Giaccone, Palermo, Italy. Email: giuseppe.lore12@gmail.com

Submitted: 2 Aug 2017; Accepted: 4 Dec 2017.

Disclosure of Conflicts of Interest: All authors have disclosed no conflicts of interest.

Funding/Support: This research received no specific grant from any funding agency in the public, commercial, or not-for-profit sectors.

Ethics Approval: All procedures involving human participants were in accordance with the ethical standards of the institutional and/or national research committee and with the 1964 Helsinki declaration and its later amendments or comparable ethical standards. All patients provided written informed consent image and data publication.
} 


\section{INTRODUCTION}

Crohn's disease (CD) is a lifelong idiopathic, often debilitating, chronic inflammatory disease of the gut. ${ }^{1-6}$ In $20 \%$ to $35 \%$ of cases, the onset of CD occurs before age 18 years, and may involve characteristically any part of the gastrointestinal tract. ${ }^{3,7}$ In adult patients, CD most commonly affects the ileum; however, in children, the large bowel is the most frequently involved segment., ${ }^{3,7}$ This difference in disease localisation can be partially related to the lymphoid follicles. The lymphoid follicles are involved in the early stage of disease, and they are less developed and still growing in size and number until puberty. ${ }^{3}$

Epidemiologically, $\mathrm{CD}$ is one of the most common gastrointestinal diseases affecting paediatric patients in the developed world. ${ }^{3-6}$ Adults and children with CD may present similar clinical features, but in paediatric patients unique complications may develop, including growth failure and delayed puberty. ${ }^{8-11}$

Clinically, patients with CD present with heterogeneous symptoms, varying from asymptomatic cases to acute abdomen events, which mimic acute appendicitis (in up to $10 \%$ of acute abdomen events), or intestinal obstruction due to strictures or intestinal perforation. ${ }^{2}$ Symptomatic patients may develop non-specific symptoms: fatigue, weight loss, gastrointestinal symptoms, such as loose stools, bloody diarrhoea, or abdominal pain. A palpable mass may be detected in the lower right quadrant, together with abdominal tenderness or perianal disease (fistulas, skin tags) ${ }^{2,6,8,12}$

Extra-intestinal manifestations are sometimes the only symptom at $\mathrm{CD}$ onset: oral ulcerations (aphthous stomatitis), clubbing, rash (erythema nodosum or pyoderma gangrenosum), eye manifestations (uveitis, episcleritis, or scleritis), jaundice or hepatomegaly, sclerosing cholangitis, or arthritis (which is typically non-erosive and asymmetric involving the large joints). Large joint affection is strongly related to disease activity grading, whereas axial skeletal affection (ankylosing spondylitis or sacroiliac joint arthritis) follows a diseaseindependent course. ${ }^{2,13}$

A peculiar characteristic of paediatric $\mathrm{CD}$ is growth failure or growth delay. It presents early with decreasing height velocity, and may progress to short stature for age, delayed bone age, and pubertal delay. ${ }^{8,14}$ The classic 'triad' of abdominal pain, diarrhoea, and weight loss has been reported in $25 \%$ of paediatric patients with $\mathrm{CD} .{ }^{14}$
Owing to the phenotypical heterogeneities of $\mathrm{CD}$, the latest European evidence-based consensus on the diagnosis and management of $\mathrm{CD}$ agreed on the lack of a single gold standard for diagnosis of $\mathrm{CD} \cdot{ }^{15}$ Histological examinations are crucial to confirm diagnosis. Endoscopy alone is unable to evaluate the overall extension or complexity of the disease, or to detect extraluminal or extra-intestinal manifestations., , 12,16,17 $^{-1}$ This position is supported by the European Society for Paediatric Gastroenterology Hepatology and Nutrition (ESPGHAN), which recommends a combination of history, physical and laboratory examination, oesophagogastroduodenoscopy and ileocolonoscopy with histology, and imaging of the small bowel for diagnosis of paediatric-onset inflammatory bowel disease (IBD). ${ }^{14}$

Biological therapies and the combined use of immune modulators have led to substantial improvements in $\mathrm{CD}$ treatment. However, therapy strategies must be tailored on disease evolution during treatment, to prolong remission, to improve quality of life, to prevent or manage hospitalisation and surgery, and to prevent disability. ${ }^{18}$

There is no consensus on the best imaging modality for evaluation of $\mathrm{CD}$ in paediatric patients, and it is often unclear which modality to choose. Radiologists must consider issues such as patient exposure to ionising radiation and tolerance of the imaging technique, in addition to diagnostic accuracy. In paediatric patients and their relatives, it is also important to consider the anxiety level and stress induced by radiological examinations. ${ }^{19-23}$ Moreover, because of the lifetime course of the disease and the need to evaluate medical therapy response, patients frequently require repeated imaging, resulting in greater cumulative lifetime radiation dose. ${ }^{3,10,24}$ Radiologists play a pivotal role in the early diagnosis and management of $\mathrm{CD}$. In order to reduce complications or hospitalisation, and to improve patient quality of life, every radiologist should be familiar with the main imaging characteristics of $\mathrm{CD}$.

\section{CONVENTIONAL RADIOLOGY}

Children with suspected CD have traditionally been investigated by barium studies, small bowel enteroclysis or small bowel follow-through, which have been considered the gold standard examinations in these cases.

Nowadays these techniques are considered obsolete, but 
they deserve to be mentioned, for the sake of radiological history. For illustrative purpose, the main small bowel enteroclysis findings (in an adult patient) are shown in Figure 1.

In small bowel follow-through, 200 to $300 \mathrm{~mL}$ of barium is orally administered, unless contra-indicated, such as in cases of suspected perforation or predisposition for airway penetration due to dysphagia, because it increases the risk of granuloma formation. ${ }^{23}$ Small bowel loops are studied under fluorographic evaluation, until the contrast medium reaches the terminal ileum and cecum. This process may take 2 to 3 hours, and may be diagnostically ineffective, because natural overlapping of the bowel loops can prevent accurate intestinal evaluation. Although small bowel follow-through affords a better study of the small bowel transit time and detecting motility disorders, small bowel enteroclysis is superior for evaluating the mucosal and transmural bowel wall features of $\mathrm{CD} .^{23-25}$

In small bowel enteroclysis, a nasojejunal tube is positioned beyond the duodenojejunal junction under fluoroscopic guidance. After this, barium (usually $300 \mathrm{~mL} 40 / 60 \mathrm{P} / \mathrm{V}$ ) to coat the bowel and $0.5 \%$ of

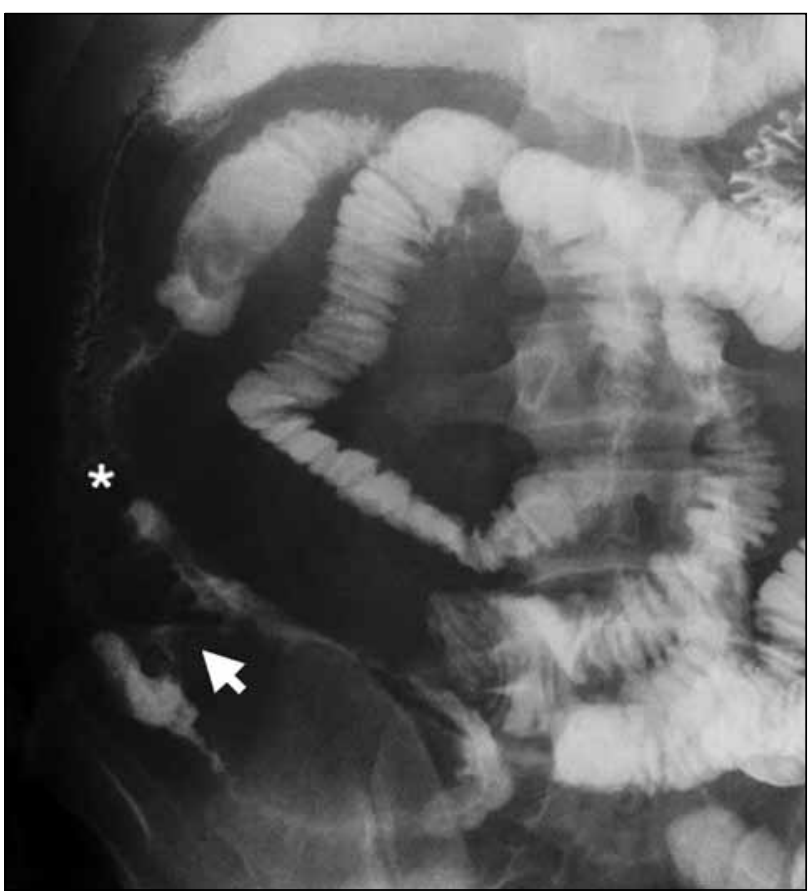

Figure 1. Radiograph showing the small bowel enteroclysis under compression in an adult patient. Stenotic bowel loops (also known as string sign) have a cobblestone appearance. A fistulous tract can be seen connecting adjacent bowel loops (arrow). Some bowel loops have become separated due to fat creeping (asterisk). methylcellulose solution $(1500 \mathrm{~mL})$ or air to distend the bowel lumen are injected. ${ }^{25,26}$ To better depict mucosal changes in patients with $\mathrm{CD}$, the patient must be adequately prepared by drinking a laxative solution on the day before the exam and fasting for at least 12 hours prior to the examination. A pro-kinetic drug may be injected approximately 20 minutes before the study, to accelerate the passage of the barium to the small bowel..$^{25}$ Multiple films are obtained with the patient in supine position, during different degrees of rotation and after compression, thus evaluating bowel mobility and flexibility..$^{23,25-28}$

Small bowel enteroclysis can detect functional signs of $\mathrm{CD}$, such as hyper- or hypo-mobility and the presence of intraluminal exudate, which results in barium flocculation appearing as blurred interfaces between the intraluminal barium and the mucosa..$^{25}$ Small bowel enteroclysis can also detect organic signs, including thickened straightened or nodular mucosal folds due to submucosal oedema secondary to lymphatic obstruction; pseudopolyps, presenting as well-defined round or oval filling defects; aphthous ulcers, presenting as shallow depressions (1-2 $\mathrm{mm}$ in diameter) with a surrounding radiolucent halo; or a combination of these features, giving a "cobblestone appearance". ${ }^{25-28}$

Small bowel enteroclysis can also readily identify strictures, mesenteric fat creeping, fistulas, and prefistulas. Strictures appear with the so-called "string sign". In cases of inflammatory functional spasm, this string sign often widens with the arrival of the peristaltic wave. ${ }^{25}$ Mesenteric fat creeping can instead be indirectly detected by the widely separated bowel loops. ${ }^{25}$ Fistulas appear as threadlike radiopaque images, linking a small bowel loop to other small bowel loops or to different organs, such as the colon, bladder, vagina, or skin. Fistulas can be indirectly visualised by premature barium filling of the fistulised organ. Pre-fistulas appear instead as a "kissing lesion". ${ }^{25-28}$ Differently from any other imaging technique, small bowel enteroclysis is unable to detect the presence of abscesses, since they are not directly connected to the bowel lumen, and thus cannot be filled with contrast medium. ${ }^{25-28}$

A large dose of radiation is needed to perform small bowel enteroclysis and small bowel follow-through. Because of this, and the advent of more modern and safe imaging modalities, conventional radiology has been almost totally abandoned in diagnosis and follow-up of CD. 


\section{ULTRASONOGRAPHY}

According to ESPGHAN, in children with suspected IBD, ultrasonography is considered a valuable screening tool for preliminary diagnostics, because of its lack of ionising radiation, non-invasiveness, low cost, and wide availability..$^{14}$ Ultrasonography has good negative predictive value for IBD, especially for CD because it accurately detects and characterises inflammation of the bowel wall and affords an assessment of the abdominal and transmural bowel abnormalities. ${ }^{29}$ Ultrasonography has a mean per-patient sensitivity of $89.7 \%$ and specificity of $95.6 \%$ and per-bowel-segment sensitivity of $73.5 \%$ and specificity of $92.9 \% .^{11}$

Healthy bowel walls have five alternating hyper/ hypo echogenic layers: the hyperechoic mucosa, the hypoechoic submucosal fold, the hyperechoic muscularis mucosae, the hypoechoic muscular layer, and the hyperechoic serosa. ${ }^{29-32}$ Absence of this physiological mural stratification and presence of mural thickening are some of the main ultrasound features associated with $\mathrm{CD}$, along with lymphadenopathy (Figures 2 and 3 ) and increased colour Doppler signal, which reflects hyperaemia. ${ }^{29,33}$ The threshold for pathological mural thickening has been reported to be from 1.5 to $3 \mathrm{~mm}$ for the terminal ileum and $<2 \mathrm{~mm}$ for the colon (Figure 2). ${ }^{29,30}$

Ultrasonography is also able to detect motility alterations, with relative decrease or lack of peristalsis as a marker of stiffness; mesenteric changes, such as mesenteric hyperplasia; hyperechogenicity with adipose tissue alteration; presence of lymphadenopathies; and transmural features, such as fistulas, abscesses, and even strictures. ${ }^{29,31}$ Abscesses and fistulas appear as hypoechoic lesions, with ill-defined walls and hyperechoic inner material (in complicated abscesses). ${ }^{29}$ Power Doppler ultrasonography can be used to identify IBD-related fistulas in both adults and in children owing to the rich microvascularisation in such fistulas. ${ }^{29,30}$

The diagnostic accuracy of ultrasonography depends on the location of the disease and the accessibility of the anatomic area. For example, the diagnostic accuracy of ultrasonography for the terminal ileum and left colon is approximately $70 \%$. It is lower for the upper small bowel and rectum, and in overweight infants..$^{34-37}$

Fasting for at least 6 hours and reducing intestinal gas, improves diagnostic accuracy of ultrasonography. Moreover, in some studies a better bowel evaluation is

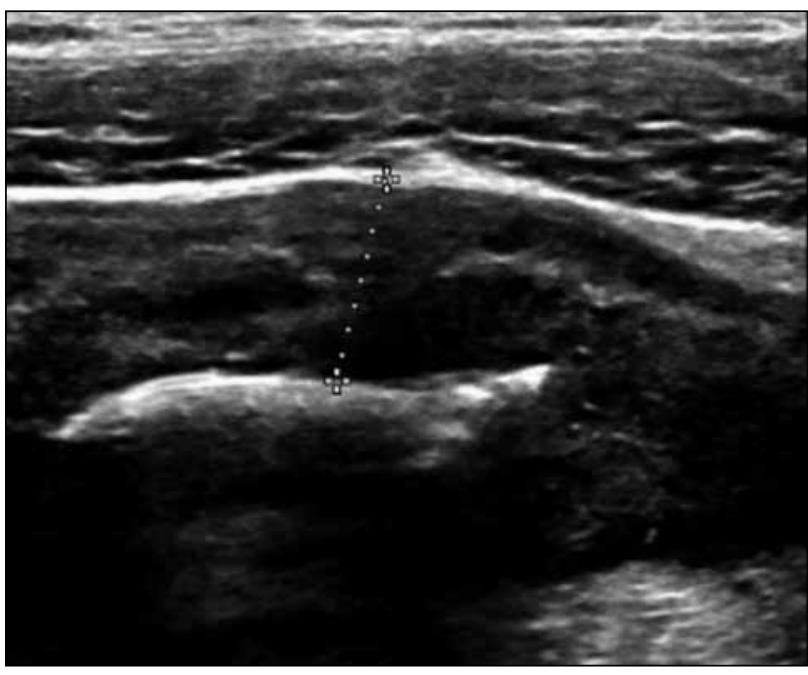

Figure 2. Ultrasonogram of a patient with Crohn's disease (male, age 6 years) using an ultrasound scanning linear high-frequency probe, showing harmonious thickening $(0.5 \mathrm{~cm}$; indicated) of the last ileal loop.

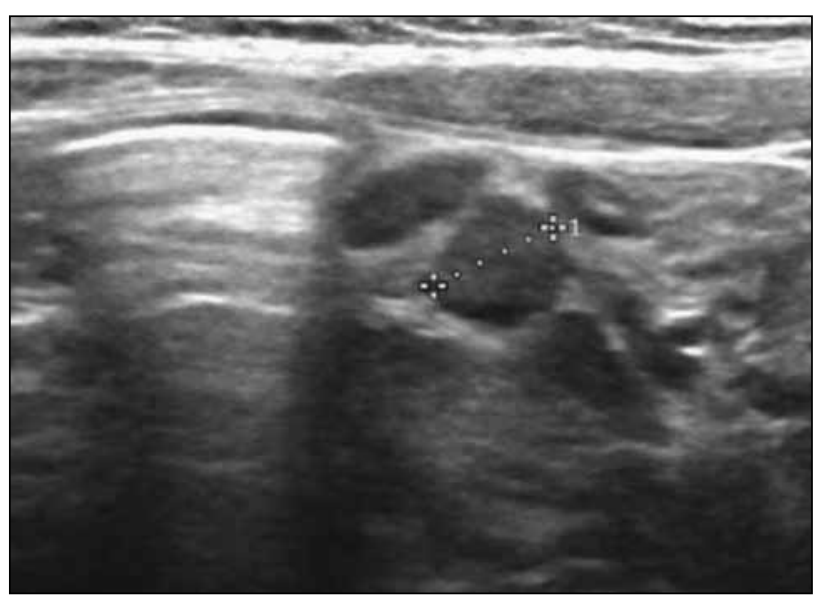

Figure 3. Ultrasonogram of a patient with Crohn's disease (male, age 6 years) using an ultrasound scanning linear high-frequency probe, showing enlarged lymph nodes (indicated) adjacent to the affected bowel loop.

achieved by the administration of an oral contrast medium, such as an iso-osmolar polyethylene glycol solution. This solution dissociates and distends overlapped intestinal loops, permitting a better visualisation of the small bowel from the angle of Treitz to the ileocecal valve. ${ }^{29,30}$ The bowel wall feature detection has been shown to be comparable to that of computed tomography (CT) and magnetic resonance imaging (MRI); however, the sensitivity of ultrasonography is lower for detecting 
complications such as abscesses or fistulas and for disease activity grading ( $84 \%$ vs. $93 \%))^{31,32,34}$

Determining disease activity is crucial for patient treatment. On ultrasonography, disease activity is derived from the evaluation of parietal wall thickening, loss of echo structure, presence of fat wrapping, presence of lymphadenopathy, and grade of vascularisation on colour Doppler examination. Colour Doppler is considered the main criterion for disease activity grading as mild (small focal area of colour signal), moderate (multiple areas of weak colour signal), and severe (multiple areas of high colour signal), although it is a subjective and operatordependent evaluation. ${ }^{38,39}$ Power Doppler is useful in discriminating inflammatory from fibrotic stenosis and internal fistulas from intra-abdominal abscesses.$^{40}$ Colour and power Doppler parameters must be optimised to detect low-velocity and low-flow states (pulse repetition frequencies 800 to $1500 \mathrm{~Hz}$, wall filter 40 to $50 \mathrm{~Hz}$, maximal colour signal gain immediately below the noise threshold, high levels of colour vs. echo priority, and colour persistence).$^{29,38-41}$

Ultrasonography relies on the experience and skill of the operator more strongly than other imaging modalities; however, according to ESPGHAN, the use of small bowel contrast ultrasonography may increase the overall sensitivity while reducing inter-observer variability for adult patients. ${ }^{14}$ Contrast-enhanced ultrasonography affords an accurate evaluation of hematic perfusion, which correlates to disease activity grading, in accordance with the enhancement pattern, allowing definition of transmural or focal fibrotic and inflammatory features. ${ }^{41-43}$

\section{COMPUTED TOMOGRAPHY}

Two CT protocols are commonly used in the diagnosis of CD: CT enteroclysis and CT enterography. Both CT protocols have similar diagnostic accuracy and

Table. Preparation for computed tomography enterography and magnetic resonance enterography ${ }^{44}$

\begin{tabular}{|c|c|}
\hline Starting from & Preparation \\
\hline $\begin{array}{l}3 \text { Days before examination } \\
12 \text { Hours before } \\
\text { examination }\end{array}$ & $\begin{array}{l}\text { - Low-fibre diet } \\
\text { - Low-fibre diet } \\
\text { - } 2 \text { L of cleansing solution (water } \\
\text { and polyethylene glycol solution) }\end{array}$ \\
\hline $\begin{array}{l}6 \text { Hours before examination } \\
30-40 \text { Minutes before } \\
\text { examination }\end{array}$ & $\begin{array}{l}\text { - Fasting } \\
\text { - } 2 \mathrm{~L} \text { of water and polyethylene } \\
\text { glycol solution }\end{array}$ \\
\hline
\end{tabular}

similar cathartic preparation $\left(\right.$ Table $\left.^{44}\right)$. CT enteroclysis requires preliminary insertion of a nasojejunal tube, under fluoroscopic guidance, to the distal portion of the duodenum then neutral contrast material is infused through the catheter. This technique provides an adequate and controlled distention of jejunal and ileal loops, providing information about bowel distensibility and detecting the presence of any strictures. ${ }^{45,46}$ The insertion of the nasojejunal tube may induce important discomfort, especially in paediatric patients, and is associated with additional radiation dose exposure to both the patient and medical staff. ${ }^{46,47}$ In contrast, CT enterography is performed after oral administration of a neutral contrast medium. ${ }^{46}$

Colonic distension may not be adequate in CT enteroclysis, so large bowel evaluation-which is the most commonly involved tract in children - may require retrograde filling of the colon with warm water. ${ }^{46}$

Administration of intravenous anticholinergic drug is recommended (unless contra-indicated) to reduce potential artefacts due to peristalsis and to obtain homogeneous small bowel distension. ${ }^{46,47}$ The CT scan is performed during breath-holding before and after contrast medium administration. ${ }^{47}$

The most common CT signs of $\mathrm{CD}$ in affected bowel loops include: bowel wall thickening $>4 \mathrm{~mm}$; pseudopolyps and ulcerations, giving a "cobblestone appearance"; segmental stenotic loops with prestenotic dilatation in cases of organic stricture; and parietal stratification and hyperenhancement, with different appearances, depending on disease pattern and activity (Figures 4 and 5). ${ }^{10,11,45-48}$ In cases of active inflammatory $\mathrm{CD}$, the mucosa and serosa layers show intense enhancement, but the other layers of bowel wall (submucosal, muscularis mucosae, and muscular layer) may show different degrees of enhancement depending on intramural oedema. In cases of chronic $\mathrm{CD}$, the involved submucosal and mucosal layers may show lower enhancement due to intramural adipose tissue infiltration: the so-called "fat halo sign". 10,11,45-48

Cross-sectional imaging modalities such as CT and MRI allow better evaluation of extraluminal features, such as mesenteric changes in the form of fat creeping. In cases of active inflammation, mesenteric fat creeping may also show various degrees of hyperdensity, which derive from oedematous imbibition. ${ }^{10,11,45-48}$ Mesenteric hyperaemia appears instead as the so-called "comb 


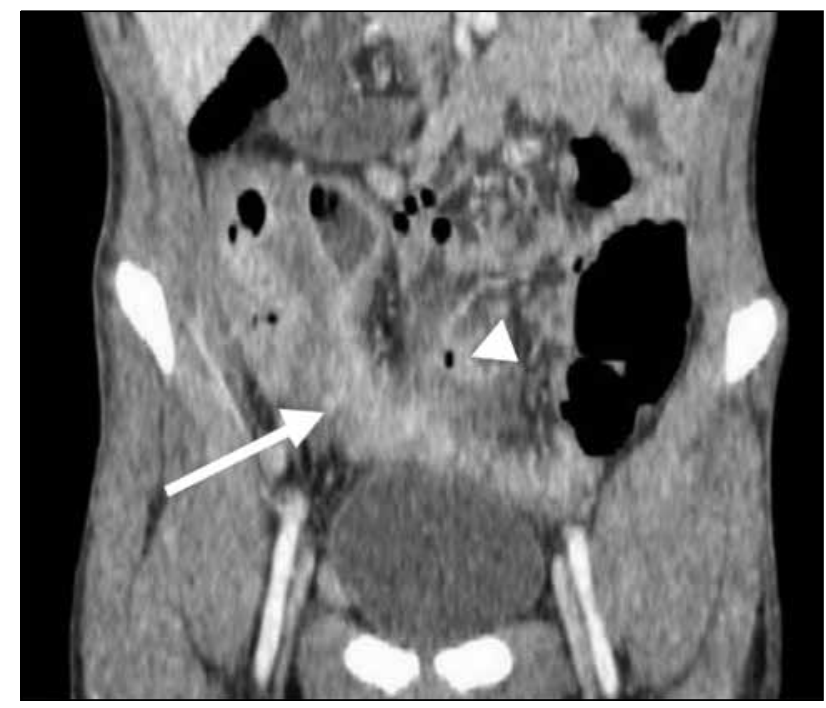

Figure 4. Coronal post-contrast computed tomography enterography image of a patient with Crohn's disease (male, age 17 years). The affected terminal ileum and bowel walls show mural thickening and contrast enhancement (arrow), as well as an abscess (arrowhead) located in the mesenteric face of the terminal ileum, within the mesenteric adipose tissue, which appears hyperdense due to intense inflammation.

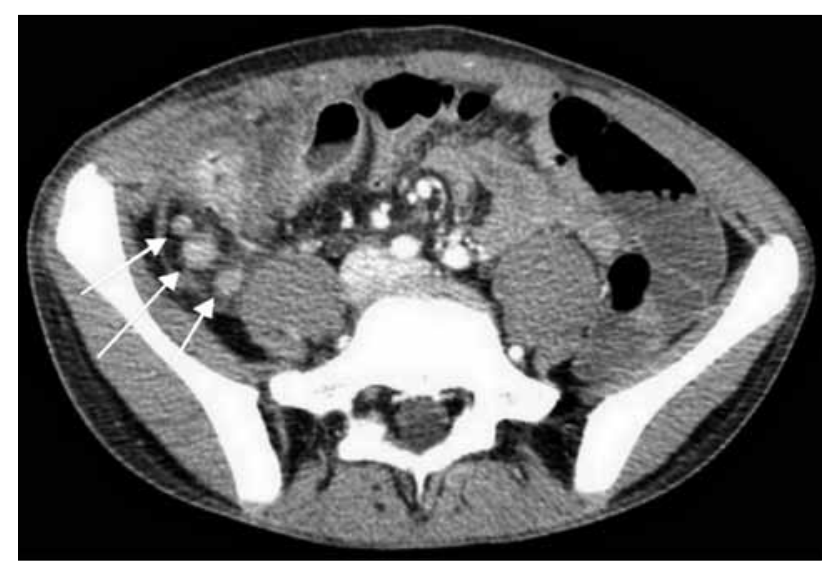

Figure 5. Axial post-contrast computed tomography enterography image of a patient with Crohn's disease (male, age 17 years), showing enlarged lymph nodes (arrows) near the affected terminal ileum, the wall of which shows mural thickening and contrast enhancement.

sign", a typical radiological feature of active $\mathrm{CD}$, due to the presence of engorged and dilated vasa recta, which penetrate the bowel wall perpendicularly to the bowel lumen, mimicking the appearance of a comb..$^{10,11,45-47}$ Lymphadenopathy is frequently depicted adjacent to the vessels and within the mesenteric tissue; the lymph nodes are considered pathological if they have a short axis $>1.5 \mathrm{~cm}$. Abscesses and fistulous tracts are easily depicted on $\mathrm{CT}$ as hyperenhancing walls with hypodense inner content. ${ }^{10,11,46}$

The diagnostic efficacy of CT enteroclysis is better than that of optical endoscopy, especially regarding detection of fistulas, abscesses, lymphadenopathy and assessment of the length of affected segments. On a per-patient basis, sensitivity of CT enteroclysis is $84.3 \%$ and specificity is $95.1 \%$. On a per-segment basis, sensitivity is $67.4 \%$ and specificity is $90.2 \% .^{11,33,49,50}$

Current recommendations from the American College of Radiology for imaging of acute events (abdominal pain, fever or leucocytosis) in children and young adults with diagnosed $\mathrm{CD}$ give equal weighting to contrastenhanced abdomen and pelvis CT and MRI. ${ }^{11}$ However, $\mathrm{CT}$ is associated with a higher radiation dose exposure from 4 to $8.6 \mathrm{mGy}$ for CT dose index and from 80 to $344 \mathrm{mGy} \cdot \mathrm{cm}$ for dose-length product. ${ }^{47}$ Radiologists and radiographers must consider dose optimisation. When possible, peak kilovoltage should be adapted to the diameter of the patient, and mAs should be adapted on the basis of scanner type, region of the body to be studied, and age of the patient. ${ }^{47}$ Moreover, the shortest rotation time available is preferred to reduce motion artefacts, and any available software should be used for dose reduction. ${ }^{47}$

When possible, CT should be avoided in children, because they have a longer remaining life expectancy than adults and intrinsic higher vulnerability to the effects of ionising radiation, and because the chronic course of $\mathrm{CD}$ requires repeated lifelong examinations..$^{20-22,51}$ Use of CT should be limited to acute situations and not in lifetime follow-up..$^{20-22,46,47,51}$

\section{MAGNETIC RESONANCE IMAGING}

According to ESPGHAN, MRI is the preferred imaging test because it can detect intestinal changes characteristic of IBD, estimate the extent of intestinal inflammation, and estimate the degree of damage..$^{14} \mathrm{~A}$ study in children by Laghi et al ${ }^{52}$ correlated the semi-quantitative score findings of MRI with endoscopic, histological, and CD activity index results. Those authors showed that MRI has a sensitivity of $84 \%$ and a specificity of $100 \%$.

The primary benefits of MRI include: superior soft tissue contrast that can assess transmural and extramural diseases; non-invasiveness; and lack of ionising radiation. 
Moreover, MRI provides functional information such as bowel motility that CT cannot obtain. ${ }^{44,52}$

As with CT examinations, MRI should be performed after bowel cleansing and distention to better evaluate the mucosal changes associated with $\mathrm{CD}$. The cathartic preparation is the same as that used for $\mathrm{CT}\left(\mathrm{Table}^{44}\right)$, and the enterography modality is preferred over enteroclysis. As with CT, retrograde filling of the large bowel with warm water is suggested. ${ }^{44,52-60}$ The use of spasmolytic agent is strongly recommended, in particular for longer sequences, such as T1-weighted (T1W) sequences, but it must be always injected after the acquisition of the "motility sequence": steady-state free-precession (SSFP) in "cine loop" mode..$^{58}$

With the patient in the prone position (facilitating the bowel loops separation and reducing breathing artefacts) and using surface multichannel body coils (12 channels), the main protocol includes preliminary thick-slab (50$\mathrm{mm}$ ) half-Fourier acquisition single-shot turbo spin echo sequence; SSFP and thick-slab cinematic steady-state sequence; single-shot fast spin echo T2-weighted (T2W) sequence with fat suppression; 3D spoiled gradient echo $\mathrm{T} 1 \mathrm{~W}$ sequence, before and after contrast medium administration; and diffusion-weighted imaging in axial and coronal planes. ${ }^{44}$

The thick-slab half-Fourier acquisition single-shot turbo spin echo sequence is a rapid image visualisation of filled small bowel loops that helps to detect if the polyethylene glycol solution has reached and distended the ileocecal junction or if there is an adequate colonic distension. ${ }^{44,57}$

The single-shot fast spin echo $\mathrm{T} 2 \mathrm{~W}$ sequences are acquired before contrast agent injection and with fat suppression. These sequences depict enteric features such as wall oedema, ulcerations, and "extra-intestinal" findings, such as free fluid or thickened and oedematous mesenteric fat stranding. Moreover, mucosal ulcerations can be better evaluated using SSFP because single-shot fast spin echo $\mathrm{T} 2 \mathrm{~W}$ images are particularly prone to intraluminal flow artefacts. ${ }^{44,53-60}$

Single-shot fast spin echo can easily detect parietal oedema, giving qualitative information about this entity by parietal hyperintensity, which is correlated to the intensity of active inflammation (Figure 6) ${ }^{44,57}$

On post-contrast T1-weighted sequences, affected bowel walls may show increased enhancement compared with

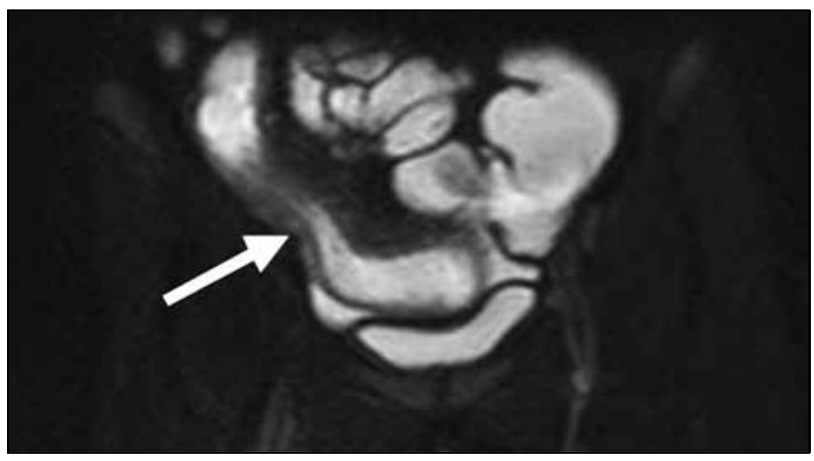

Figure 6. Coronal magnetic resonance fat-suppressed T2weighted image of a patient with Crohn's disease (female, age 10 years) showing parietal thickening and oedema (arrow).

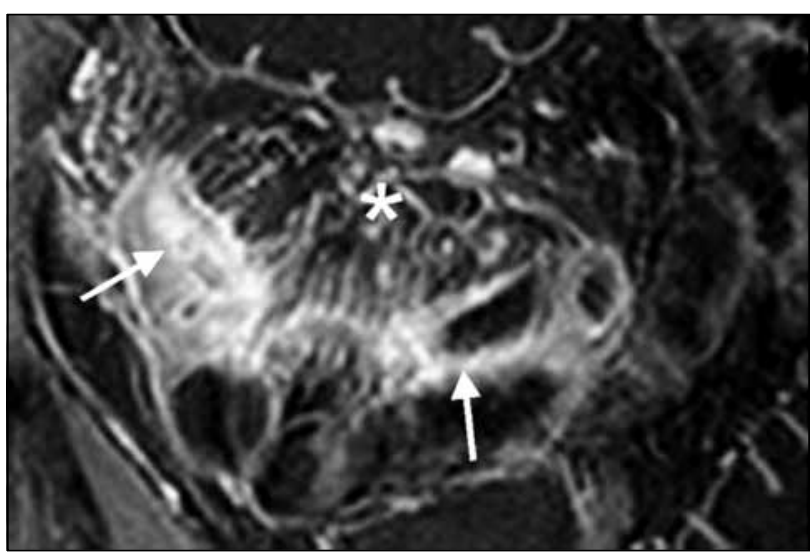

Figure 7. Coronal post-contrast T1-weighted magnetic resonance image of a patient with Crohn's disease (male, age 20 years) showing transmural enhancement of the affected bowel loop (arrows), mesenteric fat creeping, hypervascularisation (comb sign indicated by the asterisk), and enlarged lymph nodes.

adjacent healthy loops (Figure 7) with a stratified contrast enhancement pattern characterised by an inner mucosal hyperenhancing ring (hyperaemic mucosa), poor submucosal enhancement due to submucosal oedema (or lipomatosis) and an outer enhancing ring (hyperaemic serosa); with parietal transmural homogeneous contrast enhancement of the entire wall; or with low parietal inhomogeneous contrast enhancement due to fibrosis. $^{44,48,55-57}$

In cases of active inflammation, because of the increased mesenteric hematic flow, the "comb sign" (Figure 7) can be visualised on MRI. This is similar to mesenteric adipose tissue changes, which appear hyperintense on 


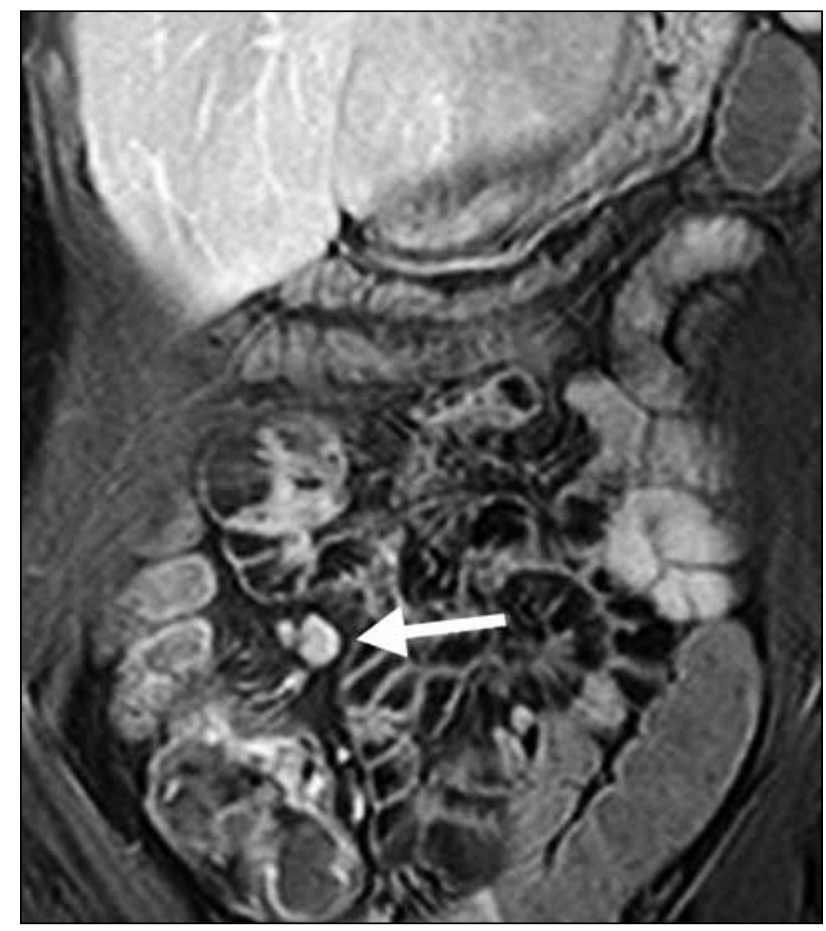

Figure 8. Coronal post-contrast T1-weighted magnetic resonance image of a patient with Crohn's disease (male, age 17 years) showing an enlarged lymph node (arrow) near the affected terminal ileum.

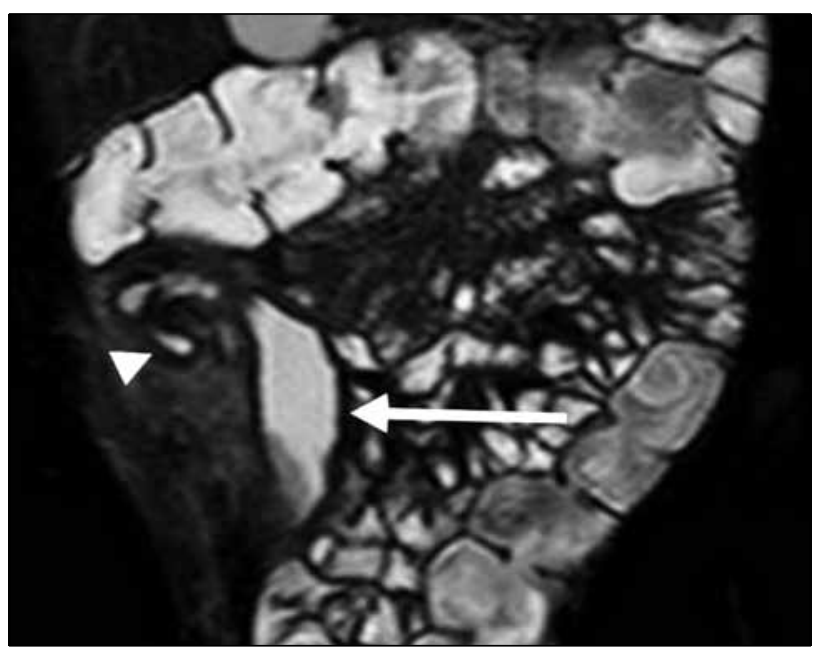

Figure 9. Coronal fat-suppressed T2-weighted magnetic resonance image of a patient with Crohn's disease (male, age 17 years) showing the rigid appearance of the terminal ileum (arrow), an abscess on the antimesenteric side (arrowhead), and adjacent hyperintense mesentery.

fat-saturated $\mathrm{T} 2 \mathrm{~W}$ images owing to oedema or slightly hypointense in cases of mesenteric fat wrapping (Figure 8). ${ }^{44,48}$ Transmural inflammatory involvement is accurately depicted in all standard MRI sequences except

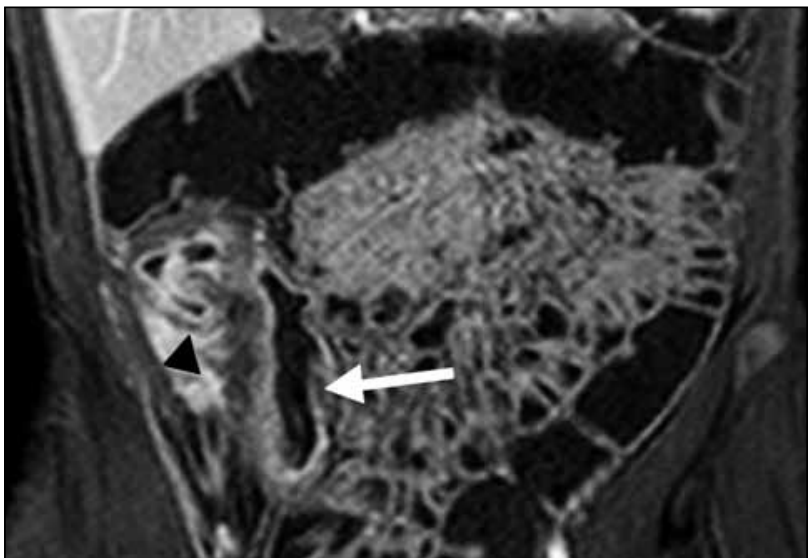

Figure 10. Coronal post-contrast T1-weighted magnetic resonance image of a patient with Crohn's disease (male, age 17 years) showing a suppurative complication (arrowhead) and the rigid terminal ileum (arrow).

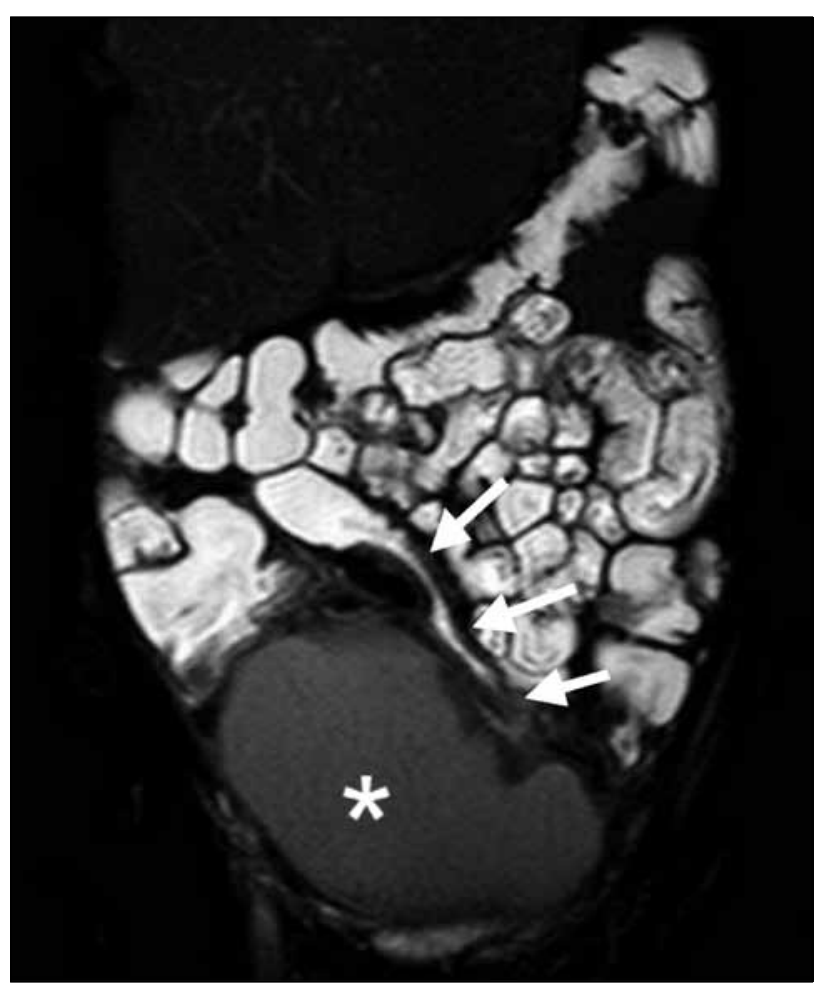

Figure 11. Coronal fat-suppressed T2-weighted magnetic resonance image of a patient with Crohn's disease (female, age 16 years) showing involvement of the terminal ileum with parietal thickening (arrows) and a huge abscess (asterisk) near the affected loop.

for SSFP, because of its typical parietal artefacts. ${ }^{44}$

Fistulas and abscesses (Figures 9-11) appear in T2W images as simple, pronged threadlike or nodular 
hyperintense structures protruding from the mesentery, whose adipose tissue signal has been suppressed by fat saturation technique (both inner granulation tissue and oedematous walls show high signal on $\mathrm{T} 2 \mathrm{~W}$ sequences). After gadolinium injection, on T1W images, fistulas and abscesses often show parietal hyperenhancement. In cases of chronic lesions, they may appear bright on non-contrast $\mathrm{T} 1 \mathrm{~W}$ images owing to their fibrotic walls, becoming gradually isointense on $\mathrm{T} 2 \mathrm{~W}$ images. ${ }^{17,44,55-57,61}$

Recently DWI sequences have been included in the routine evaluation of $\mathrm{CD}$, since the presence of hyperintense bowel walls (due to restriction of the diffusivity of water molecules) is related to a high inflammatory activity (Figure 12) ${ }^{44}$

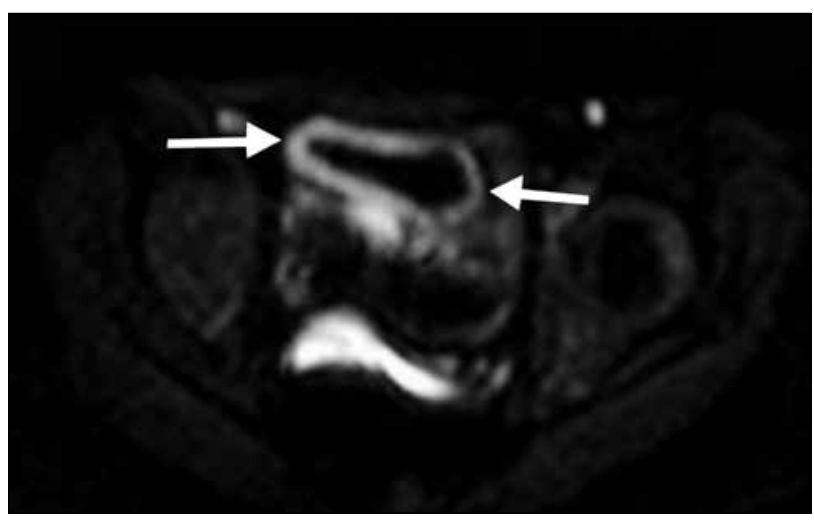

Figure 12. Diffusion-weighted magnetic resonance image of a patient with Crohn's disease (female, age 10 years) showing hyperintensity (arrows) due to severe inflammation of the affected bowel loop.

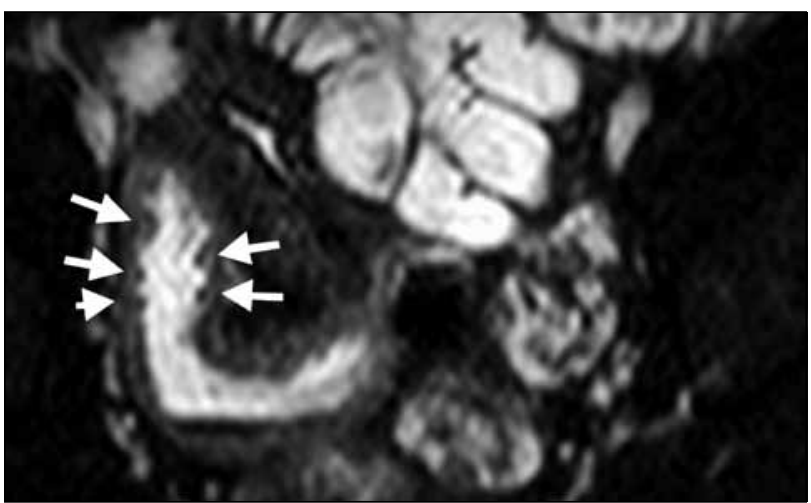

Figure 13. Coronal fat-suppressed T2-weighted magnetic resonance image of a patient with Crohn's disease (female, age 18 years) showing parietal thickening and oedema. Pseudopolyps (arrows) are also clearly visible.
Pseudopolyps can be seen in single-shot fast spin echo and SSFP images, appearing as filling defects in the lumen. They are not adequately depicted in post-contrast $\mathrm{T} 1 \mathrm{~W}$, because these typically reparative polyps do not show significant hyperaemia (Figure 13). ${ }^{57}$

Healed bowel loops may lose their "softness" and may appear as a rigid tube owing to fibrosis after severe inflammation. These appear hypointense on $\mathrm{T} 2 \mathrm{~W}$ images, and show less inhomogeneous enhancement on post-contrast $\mathrm{T} 1 \mathrm{~W}$ sequences. ${ }^{49,50}$ In cases of severe fibrotic reaction, strictures can develop as well, and must be differentiated from the functional reversible stenosis that is typical of acute inflammation. ${ }^{44}$ Strictures can be distinguished on SSFP imaging, using the "cine loop" mode, acquiring 15/25 phases of a single coronal section, thus providing optimal information about bowel wall motility. ${ }^{44,58}$ More recently, diffusion-weighted imaging has been extensively used for detecting affected bowel loops by the presence of hyperintense walls, which has been demonstrated to reflect inflammatory activity. ${ }^{44,57,59}$

As with CT, MRI affords a comprehensive evaluation of extra-intestinal CD manifestations or complications ${ }^{32,36}$ including bone involvement in IBD-related arthropathies, such as sacroiliitis or ankylosing spondylitis ${ }^{60-64}$; cholelithiasis - a frequent feature in adult patients who underwent ileocolonic surgery-or primary sclerosing cholangitis. ${ }^{56,57}$

Perianal manifestations affect up to $30 \%$ of patients with $\mathrm{CD}$, and pelvic MRI has become the imaging technique of choice in these cases. The use of endo-anal coil is not strongly recommended, because it is poorly tolerated in symptomatic patients. A simple body coil can be used to achieve good diagnostic results. Pelvic MRI has high contrast resolution for soft tissue, providing excellent anatomic detail of the anal sphincters, fistulous tracts, and their route among perianal structures, reaching $76 \%$ to $100 \%$ accuracy. ${ }^{61,65}$

The main limitation of the present review is that nuclear medicine techniques for diagnosis of $\mathrm{CD}$ were not included for comparison. However, current $\mathrm{CD}$ diagnosis tends to be more focussed on radiation-free imaging examinations, making nuclear medicine anachronistic.

\section{CONCLUSIONS}

Cross-sectional imaging has radically changed the evaluation and diagnosis of $\mathrm{CD}$, not only regarding 
anatomic and functional evaluation, but also concerning the radiation dose exposure. This is an essential issue for paediatric patients with $\mathrm{CD}$, especially considering the chronic lifelong course of the disease which requires repeated examinations.

We advise that CT should be performed only in emergency situations when acute abdomen events are suspected, or when MRI is not available. Ultrasonography provides essential information for practitioners and it is widely available; however, it is limited by many shortcomings, such as intestinal gas, operator dependency, large body habitus, and distorted anatomy or ostomies in postoperative patients.

Currently, MRI is the recommended modality for evaluation of $\mathrm{CD}$ in paediatric patients, because it is able to precisely define the presence, the extent, the grade of activity, and the principal complications of the disease, without any radiation exposure.

\section{REFERENCES}

1. Thoreson R, Cullen JJ, Pathophysiology of inflammatory bowel disease: an overview. Surg Clin North Am. 2007;87:575-85. Crossref

2. Biancone L, Pallone F, Le malattie infiammatorie croniche intestinali. Manuale di Gastroenterologia - UNIGASTRO, 2012 [in Italian]. Editrice Gastroenterologica Italiana; 2010. p 419-30.

3. Schreiber-Dietrich D, Chiorean L, Cui XW, Braden B, Kucharzik $\mathrm{T}$, Jüngert $\mathrm{J}$, et al. Particularities of Crohn's disease in pediatric patients: current status and perspectives regarding imaging modalities. Expert Rev Gastroenterol Hepatol. 2015;9:131325. Crossref

4. Levine A, Kugathasan S, Annese V, Biank V, Leshinsky-Silver E, Davidovich $\mathrm{O}$, et al. Pediatric onset Crohn's colitis is characterized by genotype-dependent age-related susceptibility. Inflamm Bowel Dis. 2007;13:1509-15. Crossref

5. Bousvaros A, Sylvester F, Kugathasan S, Szigethy E, Fiocchi $\mathrm{C}$, Colletti R, et al. Challenges in pediatric inflammatory bowel disease. Inflamm Bowel Dis. 2006;12:885-913. Crossref

6. Gupta N, Bostrom AG, Kirschner BS, Cohen SA, Abramson O, Ferry GD, et al. Presentation and disease course in early-compared to later-onset pediatric Crohn's disease. Am J Gastroenterol. 2008;103:2092-8. Crossref

7. Maccioni F, Viola F, Carrozzo F, Di Nardo G, Pino AR, Staltari I, et al. Differences in the location and activity of intestinal Crohn's disease lesions between adult and paediatric patients detected with MRI. Eur Radiol. 2012;22:2465-77. Crossref

8. Markowitz J, Grancher K, Rosa J, Aiges H, Daum F. Growth failure in pediatric inflammatory bowel disease. J Pediatr Gastroenterol Nutr. 1993;16:373-80. Crossref

9. Panes J, Bouhnik Y, Reinisch W, Stoker J, Taylor SA Baumgart DC, et al. Imaging techniques for assessment of inflammatory bowel disease: joint ECCO and ESGAR evidence-based consensus guidelines. J Crohns Colitis. 2013;7:556-85. Crossref

10. Casciani E, De Vincentiis C, Polettini E, Masselli G, Di Nardo G, Civitelli F, et al. Imaging of the small bowel: Crohn's disease in paediatric patients. World J Radiol. 2014;6:313-28. Crossref

11. Duigenan S, Gee MS. Imaging of pediatric patients with inflammatory bowel disease. AJR Am J Roentgenol. 2012;199:90715. Crossref

12. Lo Re G, Picone D, Vernuccio F, Rabita F, Cocorullo G, Salerno S, et al. Radiological follow-up of inflammatory bowel diseases. In: Lo Re G, Midiri M, editors. Crohn's Disease: Radiological Features and Clinical-surgical Correlations. Switzerland: Springer; 2015. p $137-46$.

13. Mazza M, Cilluffo MG, Cappello M. Clinical presentation of Crohn's disease. In: Lo Re G, Midiri M, editors. Crohn's Disease: Radiological Features and Clinical-surgical Correlations. Switzerland: Springer; 2015. p 7-14.

14. Levine A, Koletzko S, Turner D, Escher JC, Cucchiara S, de Ridder L, et al. ESPGHAN revised Porto criteria for the diagnosis of inflammatory bowel disease in children and adolescents. J Pediatr Gastroenterol Nutr. 2014;58:795-806.

15. Gomollón F, Dignass A, Annese V, Tilg H, Van Assche G, Lindsay Jo, et al. 3rd European evidence-based consensus on the diagnosis and management of Crohn's disease 2016: part 1: diagnosis and medical management. J Crohns Colitis. 2017;11:3-25. Crossref

16. Comelli A, Terranova MC, Scopelliti L, Salerno S, Midiri F, Lo Re G, et al. A Kernel support vector machine based technique for Crohn's disease classification in human patients. In: Barolli L, Terzo O, editors. Complex, Intelligent, and Software Intensive Systems. CISIS 2017. Advances in Intelligent Systems and Computing, Vol 611. Springer, Cham; 2017. p 262-73.

17. Maglinte DD, Gourtsoyiannis N, Rex D, Howard TJ, Kelvin FM. Classification of small bowel Crohn's subtypes based on multimodality imaging. Radiol Clin North Am. 2003;41:285303. Crossref

18. Mendolaro M, Viola A, Cappello M. Standard therapeutic approach and new therapies. In: Lo Re G, Midiri M, editors. Crohn's Disease: Radiological Features and Clinical-surgical Correlations. Switzerland: Springer; 2015. p 59-74.

19. Lo Re G, Mantia FL, Picone D, Salerno S, Vernuccio F, Midiri, M. Small bowel perforations: what the radiologist needs to know. Semin Ultrasound CT MR. 2016;37:23-30. Crossref

20. Granata C, Origgi D, Palorini F, Matranga D, Salerno S. Radiation dose from multidetector CT studies in children: results from the first Italian nationwide survey. Pediatr Radiol 2015;45:695-705. Crossref

21. Salerno $\mathrm{S}$, Marchese $\mathrm{P}$, Magistrelli $\mathrm{A}$, Tomà $\mathrm{P}$, Matranga $\mathrm{D}$, Midiri M, et al. Radiation risks knowledge in resident and fellow in paediatrics: a questionnaire survey. Ital J Pediatr. 2015;41:21. Crossref

22. Gaca AM, Jaffe TA, Delaney S, Yoshizumi T, Toncheva G, Nguyen G, et al. Radiation doses from small-bowel follow-through and abdomen/pelvis MDCT in pediatric Crohn disease. Pediatr Radiol. 2008;38:285-91. Crossref

23. Lo Re G, De Luca R, Muscarneri F, Dorangricchia P, Picone $\mathrm{D}$, Vernuccio F, et al. Relationship between anxiety level and radiological investigation. Comparison among different diagnostic imaging exams in a prospective single-center study. Radiol Med. 2016;121:763-8. Crossref

24. Salerno S, Marrale M, Geraci C, Caruso G, Lo Re G, Lo Casto A, et al. Cumulative doses analysis in young trauma patients: a singlecentre experience. Radiol Med. 2016;121:144-52. Crossref

25. Lo Re G, Vernuccio F, Picone D, Midiri F, Galfano MC, Salerno S, et al. Conventional radiology in the evaluation of the small bowel. In: Lo Re G, Midiri M, editors. Crohn's Disease: Radiological Features and Clinical-surgical Correlations. Switzerland: Springer; 2015. p 85-90.

26. Gatta G, Di Grezia G, Di Mizio V, Landolfi C, Mansi L, De Sio I, et al. Crohn's disease imaging: a review. Gastroenterol Res Pract. 2012;2012:816920. Crossref

27. Bret P, Cuche C, Schmutz G. Radiology of the Small Intestine. 
Paris: Springer; 1989. Crossref

28. CT and MRI of the small bowel. In: Herlinger H, Maglinte D, Birnbaum BA, editors. Clinical Imaging of the Small Intestine. New York: Springer; 1999. p 3-12.

29. Graziella DG, Gianluca G, Daniela B, Francesca I, Alfonso R, Giuliano G, et al. US in inflammatory bowel diseases. In: Lo Re G, Midiri M, editors. Crohn's Disease: Radiological Features and Clinical-surgical Correlations. Switzerland: Springer; 2015. p 91-8.

30. Biko DM, Rosenbaum DG, Anupindi SA. Ultrasound features of paediatric Crohn disease: a guide for case interpretation. Pediatr Radiol. 2015;45:1557-66. Crossref

31. Fraquelli M, Colli A, Casazza G, Paggi S, Colucci A, Massironi $\mathrm{S}$, et al. Role of US in detection of Crohn disease: meta-analysis. Radiology. 2005;236:95-101. Crossref

32. Panés J, Bouzas R, Chaparro M, García-Sánchez V, Gisbert JP, Martínez de Guereñu B, et al. Systematic review: the use of ultrasonography, computed tomography and magnetic resonance imaging for the diagnosis, assessment of activity and abdominal complications of Crohn's disease. Aliment Pharmacol Ther. 2011;34:125-45. Crossret

33. Horsthuis K, Bipat S, Bennink RJ, Stoker J. Inflammatory bowel disease diagnosed with US, MR, scintigraphy, and CT: metaanalysis of prospective studies. Radiology. 2008;247:64-79. Crossref

34. O'Malley ME, Wilson SR. US of gastrointestinal tract abnormalities with CT correlation. Radiographics. 2003;23:5972. Crossref

35. Kunihiro K, Hata J, Haruma K, Manabe N, Tanaka S, Chayama K. Sonographic detection of longitudinal ulcers in Crohn disease. Scand J Gastroenterol. 2004;39:322-6. Crossref

36. Maconi G, Bollani S, Bianchi Porro G. Ultrasonographic detection of intestinal complications in Crohn's disease. Dig Dis Sci. 1996;41:1643-8. Crossref

37. Gasche C, Moser G, Turetschek K, Schober E, Moeschl P, Oberhuber G. Transabdominal bowel sonography for the detection of intestinal complications in Crohn's disease. Gut. 1999;44:1127. Crossref

38. Hata J, Haruma K, Yamanaka H, Fujimura J, Yoshihara M, Shimamoto T, et al. Ultrasonographic evaluation of the bowel wall in inflammatory bowel disease: comparison of in vivo and in vitro studies. Abdom Imaging. 1994;19:395-9. Crossref

39. Maconi G, Di Sabatino A, Ardizzone S, Greco S, Colombo E, Russo A, et al. Prevalence and clinical significance of sonographic detection of enlarged regional lymph nodes in Crohn's disease. Scand J Gastroenterol. 2005;40:1328-33.

40. Robotti D, Cammarota T, Debani P, Sarno A, Astegiano M. Activity of Crohn disease: value of color-power-Doppler and contrast-enhanced ultrasonography. Abdom Imaging. 2004;29:64852. Crossref

41. Migaleddu V, Quaia E, Scanu D, Carla S, Bertolotto M, Campisi $\mathrm{G}$, et al. Inflammatory activity in Crohn's disease: CE-US. Abdom Imaging. 2011;36:142-8. Crossref

42. Serra C, Menozzi G, Labate AM, Giangregorio F, Gionchetti P, Beltrami M, et al. Ultrasound assessment of vascularization of the thickened terminal ileum wall in Crohn's disease patients using a low-mechanical index real-time scanning technique with a second generation ultrasound contrast agent. Eur J Radiol. 2007;62:11421. Crossref

43. Pallotta N, Baccini F, Corazziari E. Small intestine contrast ultrasonography (SICUS) in the diagnosis of small intestine lesions. Ultrasound Med Biol. 2001;27:335-41. Crossref

44. Lo Re G, Vernuccio F, Rabita F, Picone D, La Tona G, Salerno $\mathrm{S}$, et al. MRI enteroclysis and enterography. In: Lo Re G, Midiri M, editors. Crohn's Disease: Radiological Features and Clinical- surgical Correlations. Switzerland: Springer; 2015. p 107-13.

45. Lo Re G, Galia M, Bartolotta TV, Runza G, Taibbi A, Lagalla $\mathrm{R}$, et al. Forty-slice MDCT enteroclysis: evaluation after oral administration of isotonic solution in Crohn's disease. Radiol Med. 2007;112:787-97. Crossref

46. Lo Re G, Vernuccio F, Picone D, Rabita F, Lo Casto A, Galia M, et al. MDCT enteroclysis and enterography. In: Lo Re G, Midiri M, editors. Crohn's Disease: Radiological Features and Clinicalsurgical Correlations. Switzerland: Springer; 2015. p 99-106.

47. Toma P, Granata C, Magnano G, Barabino A. CT and MRI of paediatric Crohn disease. Pediatr Radiol. 2007;37:1083-92. Crossref

48. Quencer KB, Nimkin K, Mino-Kenudson M, Gee MS. Detecting active inflammation and fibrosis in pediatric Crohn's disease: prospective evaluation of MR-E and CT-E. Abdom Imaging. 2013;38:705-13. Crossref

49. Deepak P, Park SH, Ehman EC, Hansel SL, Fidler JL, Bruining $\mathrm{DH}$, et al. Crohn's disease diagnosis, treatment approach, and management paradigm: what the radiologist needs to know. Abdom Radiol (NY). 2017;42:1068-86. Crossref

50. Turetschek K, Schober E, Wunderbaldinger P, Bernhard C, Schima W, Puespoek A, et al. Findings at helical CT-enteroclysis in symptomatic patients with Crohn disease: correlation with endoscopic and surgical findings. J Comput Assist Tomogr. 2002;26:488-92. Crossref

51. Palorini F, Origgi D, Granata C, Matranga D, Salerno S. Adult exposures from MDCT including multiphase studies: first Italian nationwide survey. Eur Radiol. 2014;24:469-83. Crossref

52. Laghi A, Borrelli O, Paolantonio P, Dito L, Buena de Mesquita M, Falconieri $\mathrm{P}$, et al. Contrast enhanced magnetic resonance imaging of the terminal ileum in children with Crohn's disease. Gut. 2003;52:393-7. Crossref

53. Sanka S, Gomez A, Set P, Rimareva N, Davies RJ, Rolfe P, et al. Use of small bowel MRI enteroclysis in the management of paediatric IBD. J Crohns Colitis. 2012;6:550-6. Crossref

54. Dillman JR, Smith EA, Sanchez RJ, DiPietro MA, DeMatosMaillard V, Strouse PJ, et al. Pediatric small bowel Crohn disease: correlation of US and MR enterography. Radiographics. 2015;35:835-48. Crossref

55. Leyendecker JR, Bloomfeld RS, DiSantis DJ, Waters GS, Mott R, Bechtold RE. MR enterography in the management of patients with Crohn disease. Radiographics. 2009;29:1827-46. Crossref

56. Tolan DJ, Greenhalgh R, Zealley IA, Halligan S, Taylor SA. MR enterographic manifestations of small bowel Crohn disease. Radiographics. 2010;30:367-84. Crossref

57. Sinha R, Verma R, Verma S, Rajesh A. MR enterography of Crohn disease: part 2, imaging and pathologic findings. AJR Am J Roentgenol. 2011;197:80-5. Crossref

58. Froehlich JM, Waldherr C, Stoupis C, Erturk SM, Patak MA. MR motility imaging in Crohn's disease improves lesion detection compared with standard MR imaging. Eur Radiol. 2010;20:194551. Crossref

59. Kiryu S, Dodanuki K, Takao H, Watanabe M, Inoue Y, Takazoe M, et al. Free-breathing diffusion-weighted imaging for the assessment of inflammatory activity in Crohn's disease. J Magn Reson Imaging. 2009;29:880-6. Crossref

60. Paparo F, Bacigalupo L, Garello I, Biscaldi E, Cimmino MA, Marinaro E, et al. Crohn's disease: prevalence of intestinal and extraintestinal manifestations detected by computed tomography enterography with water. Abdom Imaging. 2012;37:326-37. Crossref

61. Lo Re G, Berritto D, Vernuccio F, Reginelli A, Picone D, Iacobellis F, et al. Anal Fistula in Crohn's Disease. In: Lo Re G, Midiri M, editors. Crohn's Disease: Radiological Features and Clinicalsurgical Correlations. Switzerland: Springer; 2015. p 115-26. 
62. Fornaciari G, Salvarani C, Beltrami M, Macchioni P, Stockbrügger RW, Russel MG. Musculoskeletal manifestations in inflammatory bowel disease. Can J Gastroenterol. 2001;15:399-403. Crossref

63. Charatcharoenwitthaya P, Lindor KD. Primary sclerosing cholangitis: diagnosis and management. Curr Gastroenterol Rep. 2006;8:75-82. Crossref
64. Ardizzone S, Puttini PS, Cassinotti A, Porro GB. Extraintestinal manifestations of inflammatory bowel disease. Dig Liver Dis. 2008;40 Suppl 2:S253-9. Crossref

65. Vernuccio F, Picone D, Midiri F, Salerno S, Lagalla R, Lo Re G. MR imaging of perianal Crohn disease: the role of contrastenhanced sequences. Radiology. 2017;284:921-2. Crossref 